\title{
Journal of Fluid Science and Technology
}

\section{Preface}

This special issue of the Journal contains selected papers from the Eleventh International Conference on Flow Dynamics held from October 8th to 10th, 2014 in Sendai, Japan, which was aimed at exploring new science horizon and exchanging cutting edge technologies of "Flow Dynamics". "Flow Dynamics" is a comprehensive scientific field which deals with the flow and transport phenomena concerning any fluid, any material, energy and information. Totally 390 papers were presented with three plenary lectures together in the fields of "Flow Dynamics".

This special issue presents 6 selected papers from the 50 papers in hope of a publication to the special issue which was related to the subjects on fluid science and technology and was intended to be contributed. All of the contributed papers were the extended and updated versions of their conference papers and were evaluated according to the usual JFST review process. The editorial board is grateful to the authors and the reviewers for their contributions to this special issue.

\section{Guest Editors}

Takehiko SATO, Dr. Eng., Professor, Chief Editor

Tohoku University

Yuji HATTORI, Dr. Eng., Professor

Tohoku University

Tomohide NIIMI, Dr. Eng., Professor

Nagoya University

Hidemasa TAKANA, Dr. Eng., Associate Professor

Tohoku University

Takashi TOKUMASU, Dr. Eng., Associate Professor

Tohoku University

Editors' names appear in alphabetic order except for the Chief Editor 